\title{
VIOLÊNCIA FEMINICIDA: UMA ABORDAGEM INTERSECCIONAL A PARTIR DE GÊNERO E RAÇA
}

\section{Amanda Bessoni Boudoux Salgado ${ }^{1}$}

\section{RESUMO}

A violência contra a mulher é um problema cuja complexidade exige constante debate. Recentemente, o Brasil e outros países latino-americanos incluíram em suas legislações a categoria do feminicídio, relativa ao homicídio de mulheres pelo simples fato de serem mulheres. Neste contexto, o trabalho, de cunho eminentemente teórico, pretende estabelecer vínculos entre as discriminações baseadas em gênero e raça, enfatizando como as experiências de mulheres negras diferem daquelas vivenciadas por mulheres brancas e homens negros, com apoio no conceito de interseccionalidade. Destaca-se, ao final, a necessidade de que políticas públicas rediscutam o conceito de discriminação visando à inserção do viés interseccional.

Palavras-chave: Violência; Gênero; Feminicídio; Raça; Interseccionalidade.

\section{FEMICIDE: AN INTERSECTIONAL APPROACH FROM GENDER AND RACE}

\begin{abstract}
Violence against women is a complex issue that requires constant debate. Recently, Brazil and other Latin American countries have included in their legislations the category of femicide, related to the killings of women just for being women. In this context, the paper, fundamentally theoretical, intends to establish links between gender discrimination and race discrimination, emphasizing how black women's experiences are different from those of white women and black men, based on the concept of intersectionality. In the end, we highlight the fact that public policies need to discuss the very concept of discrimination aiming the inclusion of an intersectional approach.
\end{abstract}

Key-words: violence; gender; femicide; race; intersectionality.

\section{INTRODUÇÃO}

Abordar as desigualdades significa adentrar um espectro verdadeiramente amplo de situações que, em determinados contextos históricos, sociais, políticos e econômicos, derivam do estabelecimento de relações de poder e da consequente dominação de grupos privilegiados sobre outros. A desigualdade social pode ser compreendida como um conjunto de discrepâncias entre grupos sociais, resultantes da distribuição diferenciada de recursos e serviços, tais como renda, educação e propriedade, que diretamente provocam a privação de capacidades vitais dos indivíduos, referentes a valores como saúde, integridade física e

\footnotetext{
${ }^{1}$ Doutoranda em Direito Penal, Medicina Forense e Criminologia pela Faculdade de Direito da Universidade de São Paulo (FD/USP)
} 
harmonia social (SALGADO; SAAD-DINIZ, 2017, p. 295). As diversas formas de desigualdade também estão associadas a um substrato ideológico que se traduz justamente na delimitação das diferenças e na hierarquização dos indivíduos que as representam. Definemse, então, marcadores da diferença que por longos períodos da história da humanidade foram utilizados para legitimar a negação de direitos, a opressão e a humilhação. Tais marcadores dizem respeito a elementos como sexo, gênero, raça, nacionalidade, classe social e habilidades físicas, sendo que aqui destacaremos noções e conceitos relativos predominantemente a gênero e raça, numa perspectiva interseccional que se mostra vantajosa para a construção de alternativas e políticas públicas de ação afirmativa, visando à garantia do pleno desenvolvimento subjetivo desses indivíduos.

A partir de uma discussão do conceito de interseccionalidade e do estabelecimento de diálogos entre a histórica subordinação sofrida pelos negros e pelas mulheres, trataremos do feminicídio como um fenômeno que deve ser analisado sob a ótica de diversos eixos de opressão, não somente em relação ao gênero, mas simultaneamente à perspectiva racial. A todo o momento, deve-se considerar que o grupo "mulheres" não pode ser estudado como algo homogêneo. Universalizar e generalizar as experiências de todas as mulheres, especialmente quanto à violência de gênero, significa tomar como paradigma as vivências de um subgrupo privilegiado e silenciar as vítimas de discriminação composta. Defende-se, assim, que respostas políticas com relação a raça e gênero devem ser ao mesmo tempo respostas políticas às duas formas de subordinação. Pretende-se evidenciar essa influência mútua e como a abordagem interseccional pode ser incorporada às políticas públicas para um enfrentamento mais adequado e efetivo das desigualdades.

\section{INTERSECCIONALIDADE E DIÁLOGOS ENTRE GÊNERO E RAÇA}

A referência à interseccionalidade requer cautela quanto à compreensão de seu significado. Embora seja difícil estabelecer uma definição única, pode-se considerar que há um consenso acerca de seus contornos gerais: o termo diz respeito à noção de que raça, classe, gênero, sexualidade, etnia, nacionalidade, habilidade e idade operam não como entidades unitárias e mutuamente excludentes, mas como fenômenos que se constroem reciprocamente, moldando complexas desigualdades sociais (COLLINS, 2015, p. 2). Esta conceituação pretende tratar das consequências estruturais da "interação entre dois ou mais eixos da 
subordinação" (CRENSHAW, 2002, p. 177). Introduzindo o debate sobre “interseccionalidade estrutural”, Kimberlé Crenshaw (1991, p. 1252) apontou, no início da década de 1990, o fato de que nenhuma agenda política se construía em torno das experiências, necessidades ou visões políticas das mulheres negras, uma vez que os discursos antirracismo eram protagonizados por homens negros e as demandas feministas eram definidas por mulheres brancas. Ambas as análises eram inadequadas à dupla subordinação de raça e gênero.

Patricia Hill Collins (2015, p. 3), reconhecendo a dificuldade de impor uma definição de interseccionalidade de cima para baixo, caracteriza a ideia como um projeto de conhecimento amplo, com três espécies de preocupações interdependentes: (a) a interseccionalidade como um campo de estudo (sua história, limites, debates e direções); (b) a interseccionalidade como uma estratégia analítica, que poderia, por exemplo, fornecer novos ângulos de visualização de instituições sociais, práticas, problemas sociais e outros fenômenos associados à desigualdade social; e (c) a interseccionalidade como práxis crítica, focalizando, por exemplo, como os atores sociais utilizam o conceito em projetos que buscam justiça social. O ponto central é a consideração de que, na ampla rede da interseccionalidade, diversos sistemas ou eixos de poder que constroem desigualdades se sobrepõem e se cruzam, funcionando como espaços nos quais as dinâmicas do desempoderamento se movem (CRENSHAW, 2002, p. 177).

A despeito da inexistência de definição consolidada pelos teóricos que se utilizam do viés da interseccionalidade, o fato é que ele traz vantagens para fortalecer a análise das desigualdades multidimensionais, como as que se referem à experiência cotidiana de mulheres racializadas na luta pela criação de espaços em sociedades patriarcais acostumadas a reproduzir práticas discriminatórias. Estratégias que visam ao combate de um nível de opressão isolado nunca são suficientemente bem-sucedidas e não se conectam a preocupações mais amplas de justiça social, algo que grupos de mulheres afro-americanas nos Estados Unidos denunciaram durante as décadas de 1970 e $1980 .^{2}$ Estas mulheres alertaram para a

\footnotetext{
${ }^{2}$ Em 1982, o Coletivo Combahee River de Boston circulou o paper "A Black Feminist Statement", que expunha declarações mais abrangentes da moldura que permeava o feminismo negro como um projeto de justiça social. $\mathrm{O}$ documento argumentava que estruturas baseadas somente na raça ou somente no gênero caracterizavam análises parciais e incompletas das injustiças sociais que assolavam as vidas das mulheres afro-americanas e que suas experiências eram moldadas tanto por questões de raça quanto de gênero, classe social e sexualidade. Em verdade, o surgimento da noção de interseccionalidade deve-se a esta atuação do feminismo negro norteamericano (COLLINS, 2015, p. 8).
} 
interconexão entre raça, classe, gênero e sexualidade como sistemas modulados por relações de poder. Os sistemas de poder que legitimam o racismo e o sexismo, por exemplo, estão inter-relacionados e é necessário que a proteção dos direitos humanos seja ampliada com atenção à forma como "o gênero intersecta-se com uma gama de outras identidades e ao modo pelo qual essas intersecções contribuem para a vulnerabilidade particular de diferentes grupos de mulheres" (CRENSHAW, 2002, p. 174).

As compreensões de raça e gênero como marcadores de diferenças e de dominação histórica podem ser especializadas com o reconhecimento da existência simultânea de um contrato racial e um contrato sexual que foram invisibilizados pelos teóricos clássicos do contrato social (sendo os principais Hobbes, Locke, Rousseau e Kant) e da formação do Estado moderno na teoria política ocidental, um "acordo" que pressupunha a participação dos ocupantes de posições privilegiadas (as pessoas que "importavam"). Neste sentido, Charles Mills (1997, p. 2) desenvolve a noção de contrato racial para mapear um sistema que carece de reconhecimento, aquele no qual o racismo surge como um sistema político por si mesmo, numa estrutura particular de poder de regras formais ou informais, privilégios socioeconômicos e normas de distribuição desigual de riquezas materiais e oportunidades, direitos e deveres. Segundo Mills, o propósito geral do contrato é estabelecer privilégios que diferenciem os brancos (como um grupo) dos não brancos, tais como a exploração de seus corpos, terras e recursos, e a negação das mesmas oportunidades socioeconômicas a estes. A própria utilização da categoria raça relaciona-se à construção racial por meio do contrato, sendo ele o responsável por "construir" raça e tornar todos os brancos "brancos por lei" (MILLS, 1997, p. 63).

O contrato racial determina, de fato, uma divisão do mundo entre "homens" e "nativos" ou mesmo "selvagens", sendo negado a estes qualquer status político que autorizasse sua participação na construção da sociedade, devido à sua suposta inferioridade intelectual e cognitiva. Os efeitos do contrato racial são inúmeros e permanecem latentes (frequentemente não reconhecidos) em diversos modelos de sociedade: além de provocar a demarcação dos espaços, numa espécie de preservação da geografia humana baseada na segregação racial e na manutenção da infraestrutura dos espaços predominantemente ocupados por brancos, o contrato também regulamenta e racializa os indivíduos, determinando situações de humanidade e subumanidade. Aqueles que são categorizados como "subumanos" por questões relativas ao fenótipo, à genética ou à cultura são vistos como 
detentores de um rol inferior de direitos e liberdades. Similarmente, é o caso das mulheres, excluídas do contrato social por serem consideradas passivas e incompatíveis com a vida política.

Carole Pateman elabora esta crítica ao explicar a dominação sexual e sua gênese na filosofia política moderna. Falta à teoria do contrato social também a dimensão sexual, defendendo a autora que a liberdade civil pressupõe o direito patriarcal. Esta dimensão, no entanto, não aparece nos textos dos contratualistas, que entendem a esfera privada como politicamente irrelevante, sendo igualmente irrelevante o que nela acontece. $O$ contrato original, evidentemente, não permite a atuação de mulheres. Pateman (1993, p. 21) observa: "a diferença sexual é uma diferença política; a diferença sexual é a diferença entre liberdade e sujeição. As mulheres não participam do contrato original através do qual os homens transformam sua liberdade natural na segurança da liberdade civil.” A constatação demonstra, sobretudo, o quanto a sociedade estruturou-se em termos patriarcais, com a exclusão das mulheres da vida civil por uma enorme quantidade de tempo. Os contratualistas buscam argumentar que o contrato original, como algo moderno, abandonou o patriarcado num movimento do "status para o contrato", mas Pateman (1993, p. 53) refuta esta afirmação ao concluir que o patriarcado ${ }^{3}$ permanece sendo o elemento que estrutura o capitalismo, pois, nesta sociedade, o "indivíduo" é construído com formas masculinas, e é isto que gera as opressões existentes às mulheres.

A teoria do contrato social, em sua defesa de uma sociedade civil criada por indivíduos iguais e livres para estabelecer relações por meio de contratos consensuais, apenas parece ser universal, mas não estende a característica de "indivíduos" às mulheres e aos não brancos, impossibilitados de participar da esfera civil pública. Com suas interpretações críticas da história contratual, Mills e Pateman enfatizam que ela possui, em verdade, três faces: o contrato social, o contrato racial e o contrato sexual.

\footnotetext{
${ }^{3}$ Pateman (1993, p. 56) reconhece a existência de diversas intepretações tradicionais do termo "patriarcado", e mesmo conceitos contraditórios entre si, em sua maioria relativos ao poder que o pai exerce perante o filho, transformado em direito político. Contudo, o que a autora a todo momento reforça em sua obra é que essa visão do patriarcado suprime a história de um contrato sexual que antecede a relação pai-filho. Em verdade, o que o patriarcado denota é a "tomada simultânea pelos filhos de ambas as dimensões do derrotado direito político do pai, seu direito sexual bem como seu direito paterno". Deste modo, a associação do patriarcado unicamente com a ideia de família (pai e filhos) oculta o fato de que as mulheres são dominadas antes de participarem de uma família (ou de serem mães).
} 
Muitas das barreiras jurídicas que impediam a igualdade material foram, ao longo dos anos, derrubadas. A supremacia branca não adota mais características formais e jurídicas, tal como na época da escravidão e do colonialismo europeu, em que a desumanização dos escravos era explícita, e as mulheres gradativamente puderam conquistar a igualdade jurídica em relação aos homens. No entanto, o que ainda hoje se vivencia é uma supremacia branca "de fato" e um conjunto de resquícios da subordinação feminina, que não se sustentam mais juridicamente, mas que se enraizaram nas estruturas políticas, sociais, culturais e econômicas (MILLS, 1997, p. 73). Os não brancos têm de lidar diariamente com o paradoxo de que a raça está em todo lugar e, ao mesmo tempo, em lugar nenhum. A centralidade da raça é a todo o tempo negada por aqueles que a consideram invisível exatamente porque o mundo foi (e está) construído em torno deles, e de acordo com a sua percepção cultural como grupo hegemônico.

O contrato racial e o contrato sexual deixaram de se manifestar explicitamente, mas as tensões sociais e as frequentes violações de direitos humanos de negros e mulheres demonstram que as bases ideológicas destes contratos continuam a existir de maneira não oficial, sob a máscara da igualdade universal e o mito da democracia racial ${ }^{4}$, na seletividade do sistema de justiça criminal brasileiro, no despreparo dos juízes para tratar de questões relativas à discriminação racial, na falta de capacitação de agentes públicos envolvidos no atendimento a mulheres em situação de violência, e em diversos aspectos estruturais do funcionamento do mercado, que remunera as mulheres com salários inferiores aos de homens que desempenham as mesmas funções e, dentre elas, as mulheres negras são as mais mal remuneradas. $^{5}$ Os reflexos da consideração de mulheres e negros como inferiores e subordinados constituem manifestações estruturais de poder, sendo que o mecanismo principal de reprodução de todas as formas de opressão é a violência. Trataremos deste ponto crucial que circunda as experiências das mulheres na atualidade, com foco na violência

\footnotetext{
${ }^{4}$ Sinteticamente, refere-se à conhecida noção de que o Brasil se caracteriza por um ideal de homogeneidade nacional, hibridismo demográfico e reconhecimento da importância cultural de diferentes povos para a formação do país, de forma harmônica e "democrática" (GUIMARÃES, 2011, p. 265-271).

${ }^{5}$ As mulheres recebem em média $74 \%$ do rendimento médio dos homens. Ainda, nos domicílios chefiados por mulheres, a renda per capita média daqueles chefiados por mulheres brancas é $90 \%$ maior do que os chefiados por mulheres negras, e 66,8\% maior do que a renda média per capita nos domicílios chefiados por homens negros. Os domicílios chefiados por homens brancos têm renda per capita média 10,7\% superior à dos domicílios chefiados por mulheres brancas. Similarmente, domicílios chefiados por homens negros têm renda média per capita 13,9\% maior do que os chefiados por mulheres negras (INSTITUTO DE PESQUISA ECONÔMICA APLICADA, 2011).
} 
feminicida, mantendo, no entanto, a perspectiva interseccional de raça e gênero a fim de estabelecer vínculos entre o problema da violência contra a mulher e o racismo endêmico.

\section{A VIOLÊNCIA FEMINICIDA}

O feminicídio, referido como a morte de mulheres em razão do gênero (pelo simples fato de serem mulheres) ou como resultado de abusos ocorridos no âmbito doméstico e familiar, tem sido denunciado pelos movimentos sociais feministas com o objetivo de provocar modificações legislativas que confiram visibilidade às situações de menosprezo e dominação da mulher. Esta demanda revelou-se especialmente forte nos países latinoamericanos, onde há elevados índices de assassinatos de mulheres, como no caso do México, onde de 1985 até 2014 foram registrados 50.000 feminicídios (ONU MUJERES, 2016).

O termo "femicídio" foi empregado em público por Diana Russel em 1976, referindo-se ao homicídio contra mulheres pelo fato de serem mulheres, em contraposição à definição neutra do crime. Posteriormente, em 1990, o termo é redefinido por Caputti e Russel para referir-se a uma variedade de violações contra as mulheres que incluía abusos físicos e psicológicos (como estupro, tortura, escravidão sexual, incesto, assédio sexual e outros). Segundo Russel, exemplos de femicídio incluem o apedrejamento até a morte de mulheres ${ }^{6}$; o assassinato em razão da "honra" masculina; mortes decorrentes de estupros; assassinatos de mulheres e meninas por seus maridos e namorados por terem "casos" ou serem rebeldes; mortes que resultam de mutilações genitais; mortes de escravas sexuais, mulheres traficadas e de prostitutas por seus "donos", traficantes e cafetões; e assassinatos de mulheres cometidos por serial killers (RUSSEL, 2011). O conceito abrange, portanto, todas as situações em que as mulheres são mortas em decorrência de atitudes misóginas.

A violência feminicida é compreendida por Marcela Lagarde (2007), antropóloga e pesquisadora mexicana, como a extrema violência de gênero contra as mulheres, a partir da violação de seus direitos humanos, nas esferas pública e privada. A partir da expressão "femicídio", Lagarde sugeriu o termo "feminicídio", pois, segundo sua interpretação, aquele teria como significado simplesmente a morte de mulheres. Por outro lado, "feminicídio" seria capaz de expressar as mortes ocorridas em meio a um quadro de impunidade, omissão,

\footnotetext{
${ }^{6}$ Russel (1992), na verdade, usa o termo genérico females para enfatizar que sua definição inclui bebês do sexo feminino.
} 
negligência e conivência de autoridades estatais. Não há consenso sobre a diferença entre cada um dos conceitos. Diana Russel defende a maior adequação do termo "femicídio" em virtude de seu caráter global, pois considera que não se pode chegar à conclusão de que o crime só ocorre quando há impunidade, que não é uma característica de todos os países da América Latina (RUSSEL, 2012). Lagarde confere uma conotação política ao feminicídio, tendo como panorama os assassinatos cruéis de mulheres ocorridos em Ciudad Juárez, no México, denunciados a partir de 1993, que não eram investigados e punidos pelo Estado.

As primeiras iniciativas para o reconhecimento do feminicídio partiram de associações de mulheres e organismos internacionais, que viam na proposta uma forma de controlar a polícia e os demais órgãos do sistema penal com o escopo de reduzir a impunidade desses crimes e fomentar o desenvolvimento de novas estratégias para prevenir a vitimização de mulheres (MELLO, 2015, p. 137). O feminicídio está tipificado nas legislações da Costa Rica (2007), Guatemala (2008), Colômbia (2008), El Salvador (2010), Chile (2010), México (2012), Argentina (2012), Nicarágua (2012), Bolívia (2013), Honduras (2013), Panamá (2013), Peru (2013), Equador (2014), Venezuela (2014) e Brasil (2015).

A categoria do feminicídio foi introduzida no Brasil pela Lei 13.104/2015, como qualificadora do crime de homicídio, demonstrando uma opção político-criminal do legislador sob o pressuposto de que a violência de gênero é produzida como consequência da desigualdade existente entre homens e mulheres. Definiu-se a qualificadora como o homicídio cometido "contra a mulher por razões da condição de sexo feminino" (art. 121, § $2^{\circ}$, VI, Código Penal). Inicialmente, o projeto da Comissão Parlamentar Mista de Inquérito que investigou a violência contra a mulher propôs a inserção de um parágrafo $7^{\circ}$ no tipo do homicídio qualificado, com a seguinte redação:

Denomina-se feminicídio a forma extrema de violência de gênero que resulta na morte da mulher quando há uma ou mais das seguintes circunstâncias: I relação íntima de afeto ou parentesco, por afinidade ou consanguinidade, entre a vítima e o agressor, no presente ou no passado; II - prática de qualquer tipo de violência sexual contra a vítima, antes ou após a morte: III mutilação ou desfiguração, antes ou após a morte (BRASIL, 2013, p. 1003).

Na Comissão de Constituição e Justiça, aprovou-se um substitutivo ao projeto, que definia o feminicídio como homicídio cometido "contra a mulher por razões de gênero", na ocorrência de quatro circunstâncias: (I) violência doméstica e familiar, nos termos da legislação específica; (II) violência sexual; (III) mutilação ou desfiguração da vítima; e (IV) 
emprego de tortura ou qualquer outro meio cruel ou degradante. Ao final, a Procuradoria da Mulher do Senado Federal apresentou um novo substitutivo sintetizando as circunstâncias do feminicídio em dois aspectos: a violência doméstica e familiar e o menosprezo ou discriminação à condição de mulher (CAMPOS, 2015, p. 103-115). Após envio do projeto à Câmara dos Deputados, a expressão "razões de gênero" foi substituída por "razões da condição de sexo feminino", sendo aprovado e sancionado nestes termos. O $\S 7^{\circ}$ do art. 121 do Código Penal traz, ainda, causas de aumento de pena, se o crime for praticado "durante a gestação ou nos 3 (três) meses posteriores ao parto; contra pessoa menor de 14 (catorze) anos, maior de 60 (sessenta) anos ou com deficiência; na presença de descendente ou de ascendente da vítima" (BRASIL, 2015).

A primeira hipótese da qualificadora (violência doméstica e familiar), diz respeito ao feminicídio praticado nas relações íntimas de afeto, ao passo que a segunda (menosprezo ou discriminação à condição de mulher) alude a outros tipos de comportamentos misóginos que geralmente se camuflam nas demais qualificadoras, como as de motivo torpe ou fútil. Conforme as Diretrizes Nacionais para Investigar, Processar e Julgar com Perspectiva de Gênero as Mortes Violentas de Mulheres (ONU MULHERES BRASIL, 2016), as motivações que revelam menosprezo ou discriminação à condição de mulher podem ser o sentimento de posse sobre a mulher; o controle sobre seu corpo, desejo e autonomia; a limitação da sua emancipação profissional, econômica, social ou intelectual; o tratamento da mulher como objeto sexual e outras manifestações de desprezo e ódio pela mulher e por sua condição de gênero.

Importante crítica à construção do feminicídio na lei brasileira está justamente na utilização da expressão "condição de sexo feminino", pois ignora o desenvolvimento teórico dos termos "sexo" e "gênero". O sistema sexo/gênero foi desnaturalizado por novos estudos de gênero, revelando que ambos constituem construções sociais, haja vista que, como expõe Butler, "não há nada que garanta que o ser que se torna mulher seja necessariamente uma fêmea" (BUTLER, 2010, p. 26). Carmen Hein de Campos (2015, p. 111) observa que as versões da Comissão de Constituição e Justiça e da Procuradoria da Mulher referentes ao feminicídio, que utilizavam a expressão "razões de gênero", possibilitavam uma ampliação do conceito, incluindo múltiplas identidades de gênero (transexuais, por exemplo). Por outro lado, a expressão que vigorou, "razões da condição de sexo feminino", proposta pela bancada evangélica do Congresso Nacional, restringe o alcance da norma. Nestes termos, o conteúdo 
da lei abarca somente o conceito biológico de sexo, compreendendo a identidade como algo naturalista. Nota-se que ainda que tenha atendido a demandas feministas de reconhecimento do feminicídio, a lei brasileira, em função da técnica legislativa, não restou imune a críticas, especialmente no que se refere ao conceito jurídico de mulher.

Na América Latina são distinguidos dois grandes âmbitos em que ocorrem situações de violência contra a mulher: o âmbito doméstico e familiar (a esfera privada), na qual os crimes são praticados por maridos, namorados, ex-namorados, familiares e conhecidos das vítimas; e a esfera pública, em que frequentemente se observa uma associação dos feminicídios a contextos de prostituição e comércio sexual. Todavia, esses dois âmbitos se interpenetram, o que demonstra a dificuldade de se encontrar respostas efetivas frente ao problema. A complexidade está no fato de os crimes de feminicídio serem interpretados sob a perspectiva isolada do ambiente familiar, num paradigma que equipara o crime à violência no âmbito das relações domésticas e familiares, sendo que seu fundamento vai muito além deste prisma, derivando das desigualdades de poder entre homens e mulheres, que possibilitam a dominação masculina sobre o corpo e a subjetividade da mulher. Assim, o pensamento feminista ressalta a necessidade de se analisar a situação da mulher com o fim de provocar a modificação do paradigma androcêntrico e o reconhecimento de sua liberdade não apenas no âmbito familiar, mas também na esfera pública (social, política e econômica).

Em pesquisa da Secretaria da Reforma do Judiciário realizada em 2014 e coordenada por Marta Rodriguez de Assis Machado, foram analisados em profundidade 34 processos judiciais dos estados de Mato Grosso, Minas Gerais, Bahia, Pará e Paraná, referentes a assassinatos de mulheres. O exame dos casos e as informações apresentadas na pesquisa fornecem elementos relevantes para a compreensão de como ocorre o feminicídio no Brasil. Destacou-se a diversidade dos instrumentos utilizados na prática do crime e a imposição de sofrimento às vítimas:

Faca, peixeira, canivete. Espingarda, revólver. Socos, pontapés. Garrafa de vidro, fio elétrico, martelo, pedra, cabo de vassoura, botas, vara de pescar. Asfixia, veneno. Espancamento, empalamento. Emboscada, ataques pelas costas, tiros à queima-roupa. Cárcere privado, violência sexual, desfiguração (MACHADO, 2015, p. 39).

A pesquisa também investiga os motivos das mortes das mulheres. Nos processos analisados, as razões ou "gatilhos" para os crimes incluíram (MACHADO, 2015, p. 43): revolta por término de relacionamento, ciúmes, compra de drogas, uso do gás de cozinha 
comprado pelo homem, reações a condutas da mulher (desferir tapa no rosto do marido, permitir a entrada de um homem em casa na ausência do companheiro, entre outras, que jamais justificariam uma resposta tão desproporcional como a violência fatal). A análise reforçou o que já se imaginava: que o feminicídio é a consequência final de um processo crescente de violência. Na grande maioria das vezes, há um histórico pretérito de violência que não é tratado ou denunciado, abrangendo desde o abuso psicológico até as formas mais explícitas que se acumulam e culminam na agressão física.

Ainda, a imagem que se constrói das vítimas e dos agressores é relevante para os desfechos dos processos. Frequentemente é realizada uma espécie de classificação entre as "mulheres de família" (boas mães e esposas) e aquelas que de algum modo transgrediram a imagem feminina que lhes é comum na sociedade e que são, por consequência, parcialmente responsabilizadas pela violência sofrida (são retratadas como agressoras ou provocadoras do ato), muitas vezes porque se inserem em espaços públicos comumente considerados masculinos. A estas últimas certamente não se garante o mesmo nível de proteção das primeiras. O juízo de valor sobre os hábitos, a profissão e a moradia das mulheres vítimas de algum tipo de violência é um dos fatores que mais inviabilizam uma tutela adequada, capaz de romper com os paradigmas de subordinação que motivam as legislações protetivas. A aplicação enviesada das normas de proteção, diretamente ligada ao fenômeno da discriminação interseccional, ao invés de contribuir para a modificação do modelo tradicional de sociedade (opressivo ao Outro discriminado e marginalizado), reforça uma estrutura patriarcal de traços coloniais.

É comum a vitimização secundária das mulheres sobreviventes da violência feminicida, ao terem de lidar com as instâncias oficiais de controle social e com o tratamento pouco sensibilizado de seus representantes. Ainda, o sistema de justiça criminal é orientado por narrativas produzidas para reafirmar os estereótipos que caracterizam os papéis sociais atribuídos a homens e mulheres:

Muitas vezes, além de não situar o crime em um contexto de expressão de poder patriarcal, o sistema de justiça, por seus diversos atores, chega a fazer o oposto, reafirmando discursos de culpabilização da vítima e o reconhecimento de papeis sociais que tendem a justificar as agressões (MACHADO, 2015, p. 51).

Tais papéis sociais refletem hierarquias socialmente construídas, tipicamente assimiladas pelos indivíduos em suas famílias de origem, que acabam por transmitir 
inconscientemente uma noção naturalizada de hierarquias relativas a raça, gênero, sexualidade e outras, como se observa no ideal de "chefia" da família pelo homem como personificação da autoridade. ${ }^{7}$ A violência contra a mulher é algo culturalmente enraizado que ainda se percebe com naturalidade em muitos contextos sociais, bem como nas próprias instituições do Estado ou fora dele, motivo pelo qual o direito é estabelecido como uma das ferramentas mais relevantes para modificar essa estrutura (MELLO, 2015, p. 15).

Deve-se considerar que o que não se nomeia não existe, sendo preciso, antes de tudo, nomear o problema para que ele possa começar a ser enfrentado (MELLO, 2015, p. 17). O surgimento do termo "feminicídio" nos meios de comunicação, no debate público e no cotidiano de forma geral contribui para o começo de uma discussão comprometida a respeito dos instrumentos adequados para combater essa realidade. Para Carmen Hein de Campos (2015, p. 109), o feminicídio constitui uma diferenciação legal legítima em relação ao homicídio genérico em virtude do reconhecimento jurídico dessa forma específica de violência baseada no gênero, da mesma forma como anteriormente se deu com a violência doméstica e familiar contra a mulher e a criação da Lei Maria da Penha (Lei 11.340/2006). De modo semelhante, Lagarde (2007, p. 151) defende que legislar especificamente acerca dos direitos das mulheres implica revelar que, por trás da universalidade do sujeito (implicitamente masculino) se esconde a exclusão das mulheres e a violação de seus direitos humanos.

\section{FEMINICÍDIO E DISCRIMINAÇÃO INTERSECCIONAL}

Em caráter preliminar, pode-se afirmar que os argumentos que embasaram a construção do feminicídio dizem respeito aos antecedentes históricos e dados estatísticos que demonstram a frequência com que mulheres são assassinadas em decorrência de um contexto de inferiorização, humilhação e discriminação. Segundo dados da Organização Mundial da Saúde, a taxa de feminicídios no Brasil é de 4,8 para 100 mil mulheres, a quinta maior do

\footnotetext{
${ }^{7}$ Para detalhes sobre o modo como o modelo tradicional de construção familiar está ligado à criação e reprodução de hierarquias, ver o texto de Patricia Hill Collins (1998), "It's All in the Family: Intersections of Gender, Race, and Nation".
} 
mundo. ${ }^{8}$ Somente El Salvador, Colômbia, Guatemala e a Federação Russa apresentam taxas superiores à do Brasil.

O Mapa da Violência de 2015 revelou que, entre 1980 e 2013, 106.093 mulheres morreram vítimas de homicídio no Brasil. Em 1980, o índice foi de 1.353 mulheres assassinadas, o que corresponde a 2,3 mulheres para cada grupo de 100 mil habitantes. No período indicado, a taxa apresentou um aumento de 111,1\%. Das 4.762 mulheres assassinadas no ano de 2013, 1.583 foram mortas pelo parceiro ou ex-parceiro $(33,2 \%)$, o que demonstra como a violência contra a mulher permanece extremamente atrelada à esfera familiar privada (WAISELFISZ, 2015, p. 71-76). Os dados mais recentes divulgados no Atlas da Violência 2016, realizado pelo Instituto de Pesquisa Econômica Aplicada (IPEA) em parceria com o Fórum Brasileiro de Segurança Pública, revelaram que, no ano de 2014, 4.757 mulheres foram vítimas de mortes por agressão (INSTITUTO DE PESQUISA ECONÔMICA APLICADA, 2016, p. 26).

Dados que apresentam a caracterização do perfil da maior parte das vítimas permitem uma reflexão mais acertada sob a ótica da interseccionalidade e da dominação multidimensional das mulheres negras: o Mapa da Violência constatou que a maioria das mulheres assassinadas é negra e possui idade entre 18 e 30 anos. Do ano de 2003 ao de 2013, o número de assassinatos de mulheres negras cresceu 54,2\%, aumentando de 1.864 para 2.875. Na mesma década, registrou-se um crescimento de 190,9\% na vitimização de negras, índice resultante da relação entre as taxas de mortalidade branca e negra. Para este mesmo período, o número de homicídios de mulheres brancas por ano caiu 9,8\%, diminuindo de 1.747 em 2003 para 1.576 em 2013. Os números revelam que no ano de 2013 morreram assassinadas, em proporção ao tamanho das respectivas populações, 66,7\% mais meninas e mulheres negras do que brancas. A partir da vigência da Lei Maria da Penha (Lei 11.340/2006), observou-se também uma contradição relevante: o número de vítimas cai 2,1\% entre as mulheres brancas e aumenta $35 \%$ entre as negras. ${ }^{9}$

O crescimento vertiginoso da vitimização de mulheres negras, em contraposição à redução de homicídios de mulheres brancas no período de uma década demonstra que há um

\footnotetext{
8 Deve-se observar, no entanto, que as taxas variam consideravelmente no interior do país, dada a sua heterogeneidade: o estado de Roraima, por exemplo, possui uma taxa bem acima da média nacional: 15,3 por 100 mil mulheres (WAISELFISZ, 2015).

9 Todos os dados citados constam no Mapa da Violência de 2015 (WAISELFISZ, 2015).
} 
importante componente racial na violência de gênero que deve ser profundamente investigado. Se há uma constatação de que algumas mulheres sofrem mais abusos do que outras, numa distribuição seletiva de vitimização, fica evidente que as dimensões de gênero e de raça contribuem, cada uma a seu modo, para a produção de subordinação. Kimberlé Crenshaw (2002, p. 178) observa que os exemplos mais conhecidos de opressão interseccional referem-se à violência contra as mulheres em virtude da raça ou da etnia, o que pode consistir numa inferiorização intencional, de maneira a refletir um enquadramento racial ou étnico das mulheres visando à concretização de uma violação explícita de gênero. Esta discriminação interseccional é expressa nos casos frequentes (e até mesmo recentes) de violência étnica contra as mulheres, especialmente em conflitos armados como na Bósnia, em Ruanda, no Burundi e em Kosovo. A intenção de exterminar os "inimigos" de um determinado grupo étnico ou racial geralmente inclui a estratégia de estupro massivo das mulheres daquele grupo, refletindo também o machismo e a violência de gênero:

\begin{abstract}
A violência do nacionalismo e da limpeza étnica cruza-se com a misoginia e com o desejo de humilhar o macho inimigo, levando a estupros em massa de mulheres e meninas. A tortura política, como se sabe, inclui geralmente tortura sexual tanto de homens quanto de mulheres, como se os criminosos estivessem exercendo sua dominação masculina, assim como a dominação política ou étnica (CHODOROW, 2008, p. 89).
\end{abstract}

Com efeito, a localização das mulheres não brancas na intersecção entre raça e gênero faz com que suas experiências relativas a violência, estupro e discriminação não sejam as mesmas das mulheres brancas, apesar de não ser possível realizar uma classificação das opressões como mais ou menos desumanizantes ou prejudiciais à construção do self. É necessário reconhecer que as raízes das experiências de mulheres negras são diversas, em muito derivadas da regra colonial e imperial de que o estupro era considerado um privilégio do senhor de escravos, de livre acesso aos corpos de suas "propriedades". Como observa Jill Radford, a influência desse histórico persiste ainda hoje na imagem das mulheres negras apresentada pela mídia, bem como na resposta policial e de outros agentes do Estado em relação à mulher negra em situação de violência (RADFORD; RUSSEL, 1992, p. 8). A mulher negra é julgada pelo que é, não pelo que faz.

A violência doméstica e familiar é um claro exemplo de como diferentes níveis de opressão estão interligados. Crenshaw (1991, p. 1257), em suas análises alicerçadas fundamentalmente na dinâmica social norte-americana, mas que não deixam de se aplicar à 
realidade brasileira, aponta como a violência familiar é comumente tratada como um fenômeno inexistente entre famílias negras, silenciado com o receio de que o estereótipo do homem negro como violento seja disseminado e internalizado. O peso da supremacia branca faz com que o lar se torne um "porto seguro" e que nenhuma intervenção externa seja aceita. Há uma tendência de se considerar o problema da violência contra mulheres negras apenas como mais uma manifestação do racismo, dissolvendo-se a relevância da dominação masculina como se ela fosse uma simples consequência da discriminação racial entre homens.

A discriminação interseccional é manifestada em outras situações para além da violência familiar e da violência sexual, como no emprego e na educação: com base na raça, muitas mulheres são excluídas de empregos normalmente considerados como femininos, ao mesmo tempo em que, com base no gênero, são excluídas dos empregos reservados aos homens (CRENSHAW, 2002, p. 179). ${ }^{10}$ São, portanto, pouquíssimos os espaços que mulheres racialmente identificadas conseguem ocupar no mercado de trabalho.

Fundamental é reconhecer que estratégias feministas que não questionam raça podem facilmente reproduzir e reforçar a subordinação das não brancas, ao passo que a ausência de contestação do patriarcado por parte do movimento antirracista pode reproduzir e reforçar a subordinação feminina (CRENSHAW, 1991, p. 1252). Uma análise não deve excluir a outra. A abordagem interseccional em casos de discriminação composta não implica diagnósticos acerca do principal fator discriminante, pois essa identificação quase nunca é possível. No caso das mulheres negras, as suas experiências guardam, ao mesmo tempo, similaridades e diferenças em relação àquelas vivenciadas por mulheres brancas e homens negros. A discriminação por vezes será similar à sofrida por mulheres brancas; às vezes similar à sofrida por homens negros. Frequentemente sofrerão uma dupla discriminação, com base na raça e no sexo. E, às vezes, vivenciarão discriminação como mulheres negras, não como vítimas da soma de discriminação de raça e sexo, mas singularmente como mulheres negras (CRENSHAW, 1989, p. 150).

\section{O PAPEL DAS POLÍTICAS PÚBLICAS}

\footnotetext{
${ }^{10}$ Homens também podem sofrer discriminação composta na busca por emprego quando os cargos disponíveis para mulheres não são considerados apropriados para eles, e o trabalho disponível para homens com posições privilegiadas na sociedade não é disponibilizado a homens racialmente subordinados.
} 
A perspectiva interseccional no tratamento das diversas formas de discriminação já tem sido adotada na discussão internacional dos direitos humanos. Um grande marco para esta aproximação foram as preparações para a Conferência Mundial contra o Racismo em Durban, na África do Sul, realizada em 2001, que se consolidou como a Conferência Mundial contra o Racismo, a Discriminação Racial, a Xenofobia e Intolerâncias Correlatas. Com efeito, foi a primeira conferência das Nações Unidas contra o racismo que incluiu no seu desenvolvimento a abordagem das "intolerâncias correlatas" ao racismo (de gênero, sexo, orientação sexual, idade, entre outras), introduzindo uma definição interseccional de discriminação (COLLINS; BILGE, 2016, p. 88-113). A “dispersão" da interseccionalidade no tratamento global dos direitos humanos representa uma diretriz relevante para a adoção de um novo modelo institucional para lidar internamente com desigualdades múltiplas ou complexas, as quais se tornam muito evidentes no Brasil.

Todas as situações de múltipla vulnerabilidade descritas ao longo de nossas reflexões decorrem do fato de que mulheres racializadas estão situadas de forma específica nas esferas econômica, social e política. Quando reformas são propostas em prol da mulher como se estivessem protegendo um grupo universal e homogêneo de indivíduos, de modo completamente alheio às diferenças intragrupo, é muito provável que as mulheres racialmente privilegiadas (e não apenas racialmente, mas também num contexto que envolve classe e idade, algo de que não trataremos diretamente nesta oportunidade) sejam as beneficiadas e aquelas que terão suas necessidades satisfeitas (CRENSHAW, 1991, p. 1250).

Parece ser o exemplo da Lei Maria da Penha, que apesar de estabelecer importantes medidas para a proteção da mulher em situação de violência, negligencia no plano prático a necessidade de elaborar estratégias interseccionais de proteção contra diversos níveis de opressão. A Lei 11.340/2006 menciona como diretrizes para medidas integradas de prevenção a "promoção de estudos e pesquisas, estatísticas e outras informações relevantes, com a perspectiva de gênero e de raça ou etnia, concernentes às causas, às consequências e à frequência da violência doméstica e familiar contra a mulher" (art. $8^{\circ}$, II), bem como a capacitação das Polícias Civil e Militar, Guarda Municipal, Corpo de Bombeiros e outros órgãos quanto às questões de gênero e de raça ou etnia (art. $\left.8^{\circ}, \mathrm{VII}\right)$. O mesmo dispositivo ainda prevê a "promoção de programas educacionais que disseminem valores éticos de irrestrito respeito à dignidade da pessoa humana com a perspectiva de gênero e de raça ou etnia" (art. $8^{\circ}$, VIII) e o destaque, nos currículos escolares, "para os conteúdos relativos aos 
direitos humanos, à equidade de gênero e de raça ou etnia e ao problema da violência doméstica e familiar contra a mulher" (art. $8^{\circ}$, IX) (BRASIL, 2006).

Apesar da importância de tais recomendações, pouca ênfase se dá no planejamento das políticas públicas à discriminação interseccional e à mulher negra em situação de violência. Isto é revelado, sobretudo, nas estatísticas apontadas pelo Mapa da Violência 2015 em relação ao aumento da vitimização de mulheres negras e simultânea diminuição do número de vítimas brancas: se a Lei Maria da Penha demonstrou efetividade nos anos que se seguiram à sua promulgação, o que ainda é bastante duvidoso, o foi principalmente para as mulheres brancas de classe média ou alta. Reconhece-se, sem qualquer dúvida, que houve um avanço inédito na busca pela desconstrução de imposições patriarcais de submissão da mulher e na especialização do amparo às mulheres em situação de violência, mas não menos relevante é questionar quais as características das mulheres que têm acesso à tutela, por que a maioria delas é branca e de que modo este fato se relaciona com outras perspectivas de vulnerabilidade que não estão sendo adequadamente discutidas e combatidas por meio de políticas públicas.

Há uma desigualdade no acesso à justiça, limitado pelo racismo institucional, que deve também ganhar visibilidade. Os fatores que influenciam a decisão das mulheres negras de denunciar ou não a violência sofrida refletem estes obstáculos e também o descrédito quanto ao funcionamento das instituições de segurança. Em pesquisa realizada pelo Instituto Brasileiro de Geografia e Estatística no ano de 2009, constatou-se que dentre as mulheres que sofreram agressão física praticada pelo cônjuge ou ex-cônjuge, 61,6\% das mulheres brancas buscaram o serviço policial, enquanto 51,9\% das mulheres negras o fizeram. As razões dessa discrepância incluíram o medo de represálias ou a percepção de que a intervenção policial não era necessária, respostas que não podem ser desvinculadas da relação da população negra com as instituições policiais, muito mais marcada pela repressão e reprodução de estereótipos do que pela proteção de direitos (INSTITUTO DE PESQUISA ECONÔMICA APLICADA, 2011, p. 39).

As políticas públicas devem ser pensadas considerando tais estereótipos e quem são os mais afetados pelos diversos eixos de opressão. Tanto nas discriminações de raça quanto de gênero, as ações afirmativas, por exemplo, são instrumentos úteis para combater as desigualdades e minimizar os efeitos atuais da discriminação praticada no passado. Como espécies de políticas públicas, seus objetivos incluem provocar transformações de ordem 
cultural, pedagógica e psicológica, eliminar as sequelas persistentes da discriminação do passado, implantar a diversidade e ampliar a representatividade de grupos vulneráveis nos diversos setores sociais (GOMES, 2001, p. 6-7). Novos instrumentos devem ser traçados para combater as desigualdades sociais decorrentes da discriminação interseccional, incluindo a desigualdade no acesso às políticas públicas já existentes.

\section{CONCLUSÃO}

A violência contra a mulher é um problema cuja complexidade e persistência nas diversas configurações sociais exigem um enfrentamento interseccional. A criação da Lei Maria da Penha consolidou esforços para que a violência de gênero fosse institucionalmente reconhecida como uma manifestação indigna do patriarcalismo e das desigualdades. A repercussão nacional e internacional que alcançou deve-se à demanda por um posicionamento governamental capaz de sinalizar que a violência contra mulheres é definitivamente um problema de toda a sociedade, que não se restringe ao âmbito privado e à relação de intimidade entre parceiros. Contudo, os dados referentes ao número de mulheres assassinadas no Brasil e em diversos países latino-americanos demonstram que, muito longe de ser resolvida, a questão torna-se mais intensa à medida que a violência assume consequências fatais, traduzidas nos casos de feminicídio.

Neste contexto de subjugação violenta das mulheres, não se pode ignorar o fato de que as mais afetadas e vitimizadas são mulheres racialmente identificadas, para as quais os obstáculos à busca por proteção e mesmo à decisão de denunciar abusos sofridos são potencializados pela discriminação de raça. Permite-se a conclusão de que mulheres negras encontram-se desamparadas por serem cotidianamente desconsideradas como detentoras de direitos, sendo que o discurso jurídico pode ser distorcido para reforçar as hierarquias a que estão submetidas.

Buscou-se evidenciar, em decorrência deste sistema de desigualdades sociais complexas, as seguintes hipóteses: (a) as mulheres negras das diversas classes sociais estão inseridas numa formação social em que o gênero e a raça, bem como outros marcadores, funcionam como eixos de subordinação que fazem com que suas experiências sejam diversas daquelas vivenciadas por mulheres brancas e homens negros; (b) justamente em virtude da constatação anterior, a perspectiva da interseccionalidade assume grande relevância para um 
tratamento adequado das desigualdades e o planejamento de mecanismos de enfrentamento, haja vista sua capacidade de estender horizontes protetivos e atingir indivíduos localizados nos "cruzamentos" das discriminações que normalmente são abordadas de forma isolada; e (c) deve-se reconhecer que políticas públicas que atacam somente um desses eixos não bastam, apenas contribuem para fortalecer a dominação composta daqueles que não têm a garantia de acesso igualitário aos instrumentos de proteção.

A discriminação nunca é um fenômeno motivado por um elemento singular, seu próprio significado merece uma revisão que possibilite, especialmente na prática do Judiciário, a inserção do viés interseccional na busca por reparação apropriada às vítimas de violação de direitos humanos e, fundamentalmente, por ferramentas mais efetivas de prevenção da violência.

\section{REFERÊNCIAS}

BRASIL. Decreto-Lei n. 2848, de 7 de dezembro de 1940. Código Penal. Diário Oficial da União, Poder Executivo, Rio de Janeiro, RJ, 31 dez. 1940. p. 2391. Disponível em: <http://www.planalto.gov.br/ccivil_03/decreto-lei/del2848.htm>. Acesso em: 10 maio 2017.

. Lei 11.340, de 7 de agosto de 2006. Diário Oficial da União, Poder Executivo, Brasília, DF, 08 ago. 2006. Disponível em: <http://www.planalto.gov.br/ccivil_03/_ato20042006/2006/lei/111340.htm>. Acesso em: 10 maio 2017.

. Relatório final da Comissão Parlamentar Mista de Inquérito "Com a finalidade de investigar a situação da violência contra a mulher no Brasil e apurar denúncias de omissão por parte do poder público com relação à aplicação de instrumentos instituídos em lei para proteger as mulheres em situação de violência”. Brasília, junho de 2013. Disponível em: <http://www.senado.gov.br/atividade/materia/getPDF.asp?t=130748\&>. Acesso em: 14 maio 2017.

. Lei 13.104, de 9 de março de 2015. Altera o art. 121 do Decreto-Lei no 2.848, de 7 de dezembro de 1940 - Código Penal, para prever o feminicídio como circunstância qualificadora do crime de homicídio, e o art. $1^{\circ}$ da Lei no 8.072, de 25 de julho de 1990, para incluir o feminicídio no rol dos crimes hediondos. Diário Oficial da União, Poder Executivo, Brasília, DF, 9 mar. 2015. Disponível em: <http://www.planalto.gov.br/ccivil_03/_Ato20152018/2015/lei/L13104.htm>. Acesso em: 10 maio 2017.

BUTLER, Judith. Problemas de gênero: feminismo e subversão da identidade. Rio de Janeiro: Civilização Brasileira, 2010.

CAMPOS, Carmen Hein de. Feminicídio no Brasil: uma análise crítico-feminista. Sistema Penal \& Violência: Revista Eletrônica da Faculdade de Direito do Programa de Pós- 
Graduação em Ciências Criminais da PUCRS. Porto Alegre, vol. 7, n. 1, p. 103-115, jan-jun 2015.

CHODOROW, Nancy J. Ódio, humilhação e masculinidade. In: VARVIN, Sverre;

VOLKAN, Vamik D. (orgs.). Violência ou diálogo?: reflexões psicanalíticas sobre terror e terrorismo. São Paulo: Perspectiva, 2008, p. 87-101.

COLLINS, Patricia Hill. Intersectionalityees definitional dilemmas. Annual Review of Sociology, Palo Alto, 41, p. 1-20, 2015.

. It"s All in the Family: Intersections of Gender, Race, and Nation. Hypatia, vol. 13, n. 3, Border Crossings: Multicultural and Postcolonial Feminist Challenges to Philosophy, p. 62-82, 1998.

; BILGE, Sirma. Intersectionality. Cambridge, UK; Malden, MA: Polity Press, 2016.

CRENSHAW, Kimberlé. Demarginalizing the Intersection of Race and Sex: A Black Feminist Critique of Antidiscrimination Doctrine, Feminist Theory and Antiracist Politics. The University of Chicago Legal Forum, p. 139-167, 1989.

Documento para o encontro de especialistas em aspectos da discriminação racial relativos ao gênero. Revista de Estudos Feministas, Rio de Janeiro, v. 10, n. 1, p. 171-187, 2002.

Mapping the Margins: Intersectionality, Identity Politics, and Violence against Women of Color. Stanford Law Review 43.6, p. 1241-1299, 1991.

GOMES, Joaquim B. Barbosa. Ação afirmativa e princípio constitucional da igualdade: 0 direito como instrumento de transformação social. Rio de Janeiro: Renovar, 2001.

GUIMARÃES, Antonio Sérgio Alfredo. Raça, cor, cor da pele e etnia. Cadernos de campo, São Paulo, n. 20, p. 265-271, 2011.

INSTITUTO DE PESQUISA ECONÔMICA APLICADA [et. al]. Atlas da Violência 2016. Brasília: Ipea e FBSP, 2016.

. Retrato das desigualdades de gênero e raça. 4. ed. Brasília: Ipea, 2011. Disponível em: <http://www.ipea.gov.br/retrato/pdf/revista.pdf>. Acesso em: 14 maio 2017.

LAGARDE Y DE LOS RIOS, Marcela. Por los derechos humanos de las mujeres: la Ley General de Acceso de las Mujeres a una vida libre de violencia. Revista Mexicana de Ciencias Políticas y Sociales, v. XLIX, n. 200, p. 143-165, maio-ago, 2007.

MACHADO, Marta Rodriguez de Assis. A violência doméstica fatal: o problema do feminicídio íntimo no Brasil. Brasília: Ministério da Justiça, Secretaria da Reforma do Judiciário, 2015. 
MELLO, Adriana Ramos de. Feminicidio: un análisis criminológico-jurídico de la violencia contra las mujeres. Tese (Doutorado) - Universitat Autònoma de Barcelona. 2015.

MILLS, Charles W. The racial contract. New York: Cornell University Press, 1997.

ONU MUJERES. La violencia feminicida en México, aproximaciones y tendencias 19852014, abril 2016. Disponível em:

$<$ http://www2.unwomen.org/ /media/field\%20office\%20mexico/documentos/publicaciones/2 016/02/violencia\%20feminicida $\% 20 \mathrm{en} \% 20 \mathrm{~m} \% \mathrm{C} 3 \%$ A $9 x i c 0 \% 20$ aproximaciones $\% 20 \mathrm{y} \% 20 \mathrm{ten}$ dencias\%201985_2014.pdf?v=1\&d=20160418T214527>. Acesso em: 05 maio 2017.

ONU MULHERES BRASIL. Diretrizes Nacionais para Investigar, Processar e Julgar com Perspectiva de Gênero as Mortes Violentas de Mulheres. Brasília/DF, abril de 2016. Disponível em: <http://www.onumulheres.org.br/wpcontent/uploads/2016/04/diretrizes_feminicidio.pdf >. Acesso em 20 ago. 2016.

PATEMAN, Carole. O contrato sexual. Rio de Janeiro: Paz e Terra, 1993.

RADFORD, Joan; RUSSEL, Diana. Femicide: the politics of woman killing. New York: Twayne Publishers, 1992.

RUSSEL, Diana. Defining femicide (introductory speech presented to the United Nations Symposium on femicide on 11/26/2012). Disponível em: $<\mathrm{http}: / /$ www.dianarussell.com/f/Defining_Femicide__United_Nations_Speech_by_Diana_E._H._Russell_Ph.D.pdf>. Acesso em: 05 maio 2017.

The origin and importance of the term femicide, 2011. Disponível em:

<dianarussell.com/origin_of_femicide.html>. Acesso em: 05 maio 2017.

SALGADO, Amanda Bessoni Boudoux; SAAD-DINIZ, Eduardo. Violência e vitimização como custos sociais da pobreza e da desigualdade na América Latina. In: SAAD-DINIZ, Eduardo (org.). O lugar da vítima nas ciências criminais. São Paulo: LiberArs, 2017, p. 289-314.

WAISELFISZ, Julio Jacobo. Mapa da violência 2015: homicídio de mulheres no Brasil. Cebela/FLACSO Brasil, Brasília, 2015. 